\title{
Renal dysfunction, restrictive left ventricular filling pattern and mortality risk in patients admitted with heart failure: a 7-year follow-up study
}

Morten Schou ${ }^{1,2^{*}}$, Jesper Kjaergaard ${ }^{1}$, Christian Torp-Pedersen ${ }^{3}$, Christian Hassager ${ }^{1}$, Finn Gustafsson ${ }^{1}$, Dilek Akkan ${ }^{1}$, Jacob E Moller ${ }^{1}$, Lars Kober ${ }^{1}$ and on behalf of the EchoCardiography and Heart Outcome Study (ECHOS) investigators

\begin{abstract}
Background: Renal dysfunction is associated with a variety of cardiac alterations including left ventricular (LV) hypertrophy, LV dilation, and reduction in systolic and diastolic function. It is common and associated with an increased mortality risk in heart failure (HF) patients. This study was designed to evaluate whether severe diastolic dysfunction contribute to the increased mortality risk observed in HF patients with renal dysfunction.

Methods: Using Cox Proportional Hazard Models on data $(\mathrm{N}=669)$ from the EchoCardiography and Heart Outcome Study (ECHOS) study we evaluated whether estimated glomerular filtration rate (eGFR) was associated with mortality risk before and after adjustment for severe diastolic dysfunction. Severe diastolic dysfunction was defined by a restrictive left ventricular filling pattern (RF) (=deceleration time $<140 \mathrm{~ms}$ ) by Doppler echocardiography.

Results: Median eGFR was $58 \mathrm{ml} / \mathrm{min} / 1.73 \mathrm{~m}^{2}$, left ventricular ejection fraction was $33 \%$ and RF was observed in $48 \%$. During the 7 year follow up period 432 patients died. Multivariable adjusted eGFR was associated with similar mortality risk before (Hazard Ratio(HR) eGFR $10 \mathrm{ml}$ increase: 0.94 (95\% Cl: 0.89-0.99, P=0.024) and after (HR eGFR $10 \mathrm{ml}$ increase: 0.93 (0.89-0.99), $\mathrm{P}=0.012$ ) adjustment for RF (HR: $1.57(1.28-1.93), \mathrm{P}<0.001)$.

Conclusions: In patients admitted with HF RF does not contribute to the increased mortality risk observed in patients with a decreased eGFR. Factors other than severe diastolic dysfunction may explain the association between renal function and mortality risk in HF patients.
\end{abstract}

Keywords: Estimated glomerular filtration rate, Restrictive filling pattern, Heart failure, Mortality risk

\section{Background}

An association between renal dysfunction and mortality risk has been documented several times in heart failure (HF) patients [1-6]. The cause of excess mortality in these patients is, however, poorly understood as is the interplay between renal dysfunction and other prognostic factors in HF. Several explanations - e.g. increased atherosclerotic burden, impaired central haemodynamics and increased neurohormonal activity - have been proposed for the increased mortality risk in HF patients with a poor renal function [7-17]. However, an observational follow up

\footnotetext{
* Correspondence: m.schou@dadlnet.dk

'Department of Cardiology, The Heart Centre and University of Copenhagen, Rigshospitalet, DK-2100 Copenhagen, Denmark

2Department of Cardiology and Endocrinology, Hillerod University Hospital, DK-3400 Hillerod, Denmark

Full list of author information is available at the end of the article
}

study, where all proposed prognostic factors in HF have been included has not yet been conducted in a large HF cohort and consequently it is still unclear if the effect of renal function and mortality risk can be explained by e.g. impaired diastolic function or other important confounders [18].

In patients with chronic kidney disease diastolic dysfunction may be present in up to $70 \%$ of the patients [19] and a link between renal dysfunction and left ventricular hypertrophy resulting in diastolic dysfunction may also be present in patients with HF, where renal dysfunction is often present. In theory, renal dysfunction could contribute to the heart failure syndrome, negatively affecting prognosis, by adding the burden of impaired filling to patients suffering from HF. However, studies with long-term follow-up and information on 
systolic, diastolic and renal function are lacking in HF patients.

To address these issues we used data from the EchoCardiography and Heart Outcome Study (ECHOS) study to evaluate whether the increased mortality risk observed in HF patients with renal dysfunction potentially could be explained by severe diastolic dysfunction.

\section{Methods}

\section{Study population and patient selection}

The ECHOS study was a trial of the central symphatolytic agent CHF1035 versus placebo in patients with HF. The trial design and results have been described in detail previously [20,21]. Briefly, from 2001 to 2002, 3954 consecutive patients admitted with congestive HF were screened in 43 hospitals in Scandinavia, primarily Denmark. Congestive HF was defined as current NYHA functional class II-IV, requiring intravenous treatment with diuretic and at least one episode of dyspnoea or fatigue at rest or during slight exertion within the last month corresponding to at least NYHA class III or IV). Demographic variables and comorbid conditions were registered (Table 1). A Wall Motion Index $(\mathrm{WMI}) \leq 1.2 （ \approx$ Left ventricular ejection fraction $(\operatorname{LVEF}) \leq 35 \%)$ was found in 1831 patients and 1000 patients were eventually randomized in the drug trial. Patients were randomized to either placebo $(\mathrm{N}=499)$ or a selective agonist of the pre-synaptic DA2- and $\alpha 2-$ receptors $(\mathrm{N}=501)$ and were followed for at least 12 months. The study drug had no effect on overall mortality or morbidity [20]. The study was carried out in accordance with the Declaration of Helsinki II and the study was approved by The Ethical Committee of Copenhagen, Denmark. The current study is based on data obtained from screening of patients admitted with HF to the departments participating in the ECHOS study. Hence, this study included both patients with systolic and diastolic HF.

For the present analyses, patients were selected as follows: Of the initial 3954 patients screened for the ECHOS study, only Danish patients were available for the extended follow up $(\mathrm{N}=3078)$. Of these patients 2881 patients had measurement of LVEF. Both LVEF and serum(s)-creatinine were available in 2012 patients. $\mathrm{S}$-creatinine together with left ventricular filling pattern obtained by the flow velocity across the mitral valve in the apical 4-chamber view were available in 669 patients (Table 1). Included $(\mathrm{N}=669)$ and excluded $(\mathrm{N}=2212)$ patients were subsequently compared concerning important demographic variables (age, sex, NYHA class, WMI, eGFR, frequency of RF (available in 967 patients), and mortality risk (see Results)).

\section{Echocardiography}

Echocardiography was performed within the first 7 days after admission. Patient history and a physical examination were obtained and all patients underwent 2-dimensional baseline transthoracic echocardiography in order to determine LVEF. In addition to standard 2-dimensional echocardiography the centers were also encouraged to perform Doppler ultrasound and M-mode examinations on a voluntary basis. Doppler flow recordings of sufficient quality were available for 972 patients. Echocardiograms were digitized and subsequently analyzed by two experienced investigators (D.A. and J.K.) who were blinded to all clinical data. Analyses of wall motion index (WMI) were evaluated separately in a core lab. LVEF was assessed semiquantitatively from WMI using a 16-segment model. Using a reverse scoring system, each of the 16 left ventricular segments were assigned a descending score from 3 to -1 , according to myocardial function (hyperkinesis $=3$, normokinesis $=2$, hypokinesis $=1$, akinesis $=0$, paradoxical motion $=-1$ ). WMI was calculated by dividing the sum of the scores by the number of segments analyzed. Left ventricular filling pattern was obtained by measuring the diastolic flow velocities across the mitral valve in the apical 4- chamber view. Effort was made to detect maximal flow velocities during diastole with the sample volume placed at the tip of the mitral leaflets. Deceleration time of early filling (DT), peak flow velocity in early diastole ( $E$ velocity) and peak flow velocity at atrial contraction (A velocity) were measured as the averages of five consecutive cardiac cycles. DT was measured similarly in patients with atrial fibrillation/-flutter, but was based on averages of 5 to 10 consecutive cardiac cycles. Cardiac cycles with fusion of early and late velocities or with nonlinear deceleration slope were excluded. RF was considered present when deceleration time was $\leq 140 \mathrm{~ms}$ [21].

\section{Estimated glomerular filtration rate}

Estimated glomerular filtration rate (eGFR) was calculated by the four-component Modification of Diet in Renal Disease (MDRD) equation incorporating age, race, sex and s-creatinine concentration [16]: eGFR $=186$ * $(\mathrm{s} \text {-creatinine [in milligrams per decilitre]) })^{-1.154 *}$ (age $[$ in years $])^{-0.203}$. For women the product of the equation has to be multiplied by a correction factor of 0.742. The equation has been evaluated in heart failure patients [22].

\section{End points}

The primary end-point was death from all causes obtained from the Danish Central Personal Registry, where all deaths in Denmark are registered within 2 weeks. Thus, in (May 2008) the central registry provided 7 years (median) of follow-up (range: 5.8 to 7.4 years) for patients included in the current analyses. One patient emigrated and was censored at time of emigration (after 472 days), no other patients were lost to follow-up. 
Table 1 Patients characteristics according to groups of eGFR ( $\mathrm{N}=669)$

\begin{tabular}{|c|c|c|c|c|c|}
\hline Demographic data & $\begin{array}{c}\text { eGFR: }<45.0 \mathrm{ml} / \mathrm{min} \\
1.73 \mathrm{~m}^{2} \mathrm{~N}=191\end{array}$ & $\begin{array}{c}\text { eGFR: } 45.0-59.9 \mathrm{ml} / \mathrm{min} \\
1.73 \mathrm{~m}^{2} \mathrm{~N}=162\end{array}$ & $\begin{array}{c}\text { eGFR: } 60.0-74.9 \mathrm{ml} / \mathrm{min} \\
1.73 \mathrm{~m}^{2} \mathrm{~N}=176\end{array}$ & $\begin{array}{c}\text { eGFR: } \geq 75.0 \mathrm{ml} / \mathrm{min} \\
1.73 \mathrm{~m}^{2} \mathrm{~N}=140\end{array}$ & $P$ value \\
\hline \multicolumn{6}{|l|}{ Clinical variables: } \\
\hline Age, years & $78(63-91)$ & $75(56-89)$ & $72(55-90)$ & $68(46-84)$ & $<0.001$ \\
\hline Female sex, $\%$ & 45 & 43 & 30 & 34 & 0.006 \\
\hline $\mathrm{BMI}, \mathrm{kg} / \mathrm{m}^{2}$ & $25(19-26,26-36)$ & $26(17-37)$ & $26(18-34)$ & $27(20-41)$ & 0.058 \\
\hline Smoking,\% & 20 & 23 & 31 & 43 & $<0.001$ \\
\hline History of HF,\% & 76 & 76 & 63 & 54 & $<0.001$ \\
\hline NYHA Class,\%: & & & & & 0.052 \\
\hline । & 7 & 9 & 15 & 15 & \\
\hline$\|$ & 65 & 65 & 62 & 65 & \\
\hline III & 25 & 25 & 19 & 20 & \\
\hline IV & 3 & 1 & 4 & 0 & \\
\hline \multicolumn{6}{|l|}{ Comorbidity: } \\
\hline Diabetes,\% & 22 & 15 & 13 & 15 & 0.049 \\
\hline COPD, $\%$ & 20 & 19 & 23 & 26 & 0.111 \\
\hline $\mid H D, \%$ & 54 & 58 & 45 & 39 & 0.002 \\
\hline Previous MI,\% & 32 & 35 & 30 & 25 & 0.139 \\
\hline Hypertension,\% & 32 & 32 & 25 & 31 & 0.484 \\
\hline Chronic AF,\% & 26 & 21 & 28 & 19 & 0.313 \\
\hline Paroxysmal AF,\% & 19 & 22 & 21 & 21 & 0.801 \\
\hline \multicolumn{6}{|c|}{ Echocardiographic variables: } \\
\hline WMI, index: & $1.2(0.5-2.0)$ & $1.1(0.5-2.0)$ & $1.3(0.5-2.0)$ & $1.4(0.6-2.0)$ & 0.093 \\
\hline LVEDD, mm & $57(42-75)$ & $59(41-77)$ & $58(42-70)$ & $57(42-78)$ & 0.878 \\
\hline $\mathrm{A}, \mathrm{m} / \mathrm{s}$ & $0.63(0.30-1.15)$ & $0.76(0.30-1.33)$ & $0.62(0.32-1.03)$ & $0.62(0.33-0.96)$ & 0.055 \\
\hline E/A-ratio & $1.34(0.56-3.37)$ & $1.11(0.57-3.11)$ & $1.12(0.58-3.03)$ & $1.40(0.60-3.12)$ & 0.4639 \\
\hline \multicolumn{6}{|c|}{ Medication (discharge): } \\
\hline ACE-I, \% & 51 & 70 & 63 & 45 & 0.309 \\
\hline $\mathrm{ARB}, \%$ & 10 & 9 & 5 & 9 & 0.266 \\
\hline Beta blockers,\% & 49 & 57 & 45 & 42 & 0.097 \\
\hline Diuretics,\% & 95 & 93 & 89 & 89 & 0.017 \\
\hline Digoxin,\% & 37 & 39 & 47 & 36 & 0.634 \\
\hline Statin,\% & 17 & 20 & 16 & 23 & 0.470 \\
\hline Nitrates, $\%$ & 28 & 23 & 12 & 17 & 0.001 \\
\hline
\end{tabular}

eGFR = estimated glomerular filtration rate; BMI = Body Mass Index; History of HF = history of heart failure; NYHA class = New York Heart Association; COPD = chronic obstructive pulmonary disease; $\mathrm{IHD}=$ ischemic heart disease; Previous $\mathrm{MI}=$ previous myocardial infarction; Chronic $\mathrm{AF}=$ chronic atrial fibrillation; Paroxysmal $\mathrm{AF}=$ paroxysmal atrial fibrillation; $\mathrm{WMI}=$ wall motion index; $\mathrm{LVEDD}=$ left ventricular enddiastolic diameter; $\mathrm{A}=$ late atrial mitral Doppler peak flow velocity; $\mathrm{E} / \mathrm{A}$-ratio = the ratio of early (E) to late atrial (A) mitral Doppler peak flow velocity; $\mathrm{ACE}-\mathrm{I}=$ angiotensin converting enzyme inhibitor; $\mathrm{ARB}=$ angiotensin II receptor blocker.

\section{Statistics}

Patients, were grouped by levels of eGFR: Group I: eGFR $<45.0 \mathrm{ml} / \mathrm{min} / 1.73 \mathrm{~m}^{2}$, Group II: eGFR 45.0$59.9 \mathrm{ml} / \mathrm{min} / 1.73 \mathrm{~m}^{2}$, Group III: eGFR $60.0-74.9 \mathrm{ml} /$ $\mathrm{min} / 1.73 \mathrm{~m}^{2}$ and Group IV: eGFR $\geq 75.0 \mathrm{ml} / \mathrm{min} / 1.73 \mathrm{~m}^{2}$. Proportions are presented as percent and continuous variables are presented as medians with $95 \%$ confidence intervals. Baseline characteristics were compared between groups using chi-square test for discrete variables and, Cochran-Armitage Trend Test, Kruskal Wallis tests (nonparametric) or one-way ANOVA (parametric) for continuous variables, as appropriate. The associations between eGFR and mortality were examined using Cox proportional hazards model. Survival curves were generated by means of Kaplan-Meier estimates, and differences in survival were compared using log-rank test. Cox proportional 
multivariate hazard models were fitted with the use of available clinical covariates (eGFR, age, sex, body mass index, smoking, RF, WMI, NYHA class, diabetes, history of hypertension, history of chronic obstructive pulmonary disease, history of ischemic heart disease, previous MI, and atrial fibrillation). The association between eGFR and mortality risk was evaluated by a univariate analysis (model 1), after adjustment for all covariates except RF (model 2) and after adjustment for all covariates including RF (model 3). The association between RF and mortality risk was evaluated in a similar way (model 4-6). The assumptions underlying the Cox proportional-hazards model (proportional hazards, lack of interaction, and linearity of continuous variables) were tested and found to be valid. A P-value $<0.05$ was considered significant (two-sided). Analyses were performed using Statistical Analysis Software (SAS 9.1, Cary, NC, USA).

\section{Results}

\section{Patients characteristics}

Patient characteristics according to groups of eGFR are presented in Table 1 and Figures 1, 2, 3. Patients with a low eGFR (group IV) were older $(\mathrm{P}<0.001)$, more frequently female $(\mathrm{P}<0.001)$, and less frequently smokers $(\mathrm{P}<0.001)$. More frequently patients with low eGFR suffered from diabetes $(\mathrm{P}=0.049)$, had a history of HF $(\mathrm{P}<0.001)$ and ischemic heart disease $(\mathrm{P}=0.002)$. Finally, patients with a low eGFR were treated with nitrates $(P=0.001)$ and diuretics $(P=0.017)$ more frequently. None of the Doppler parameters were affected by eGFR (Figures 1, 2, 3), except the prevalence of $\mathrm{RF}(\mathrm{P}=0.049)$, which increased with increasing eGFR (Figure 3 ).

Included ( $\mathrm{N}=669$ ) versus excluded ( $\mathrm{N}=2212$ ) patients The included and excluded patients did not differ with regard to age $(\mathrm{P}=0.36)$, sex $(\mathrm{P}=0.54)$, eGFR $(\mathrm{P}=0.23)$

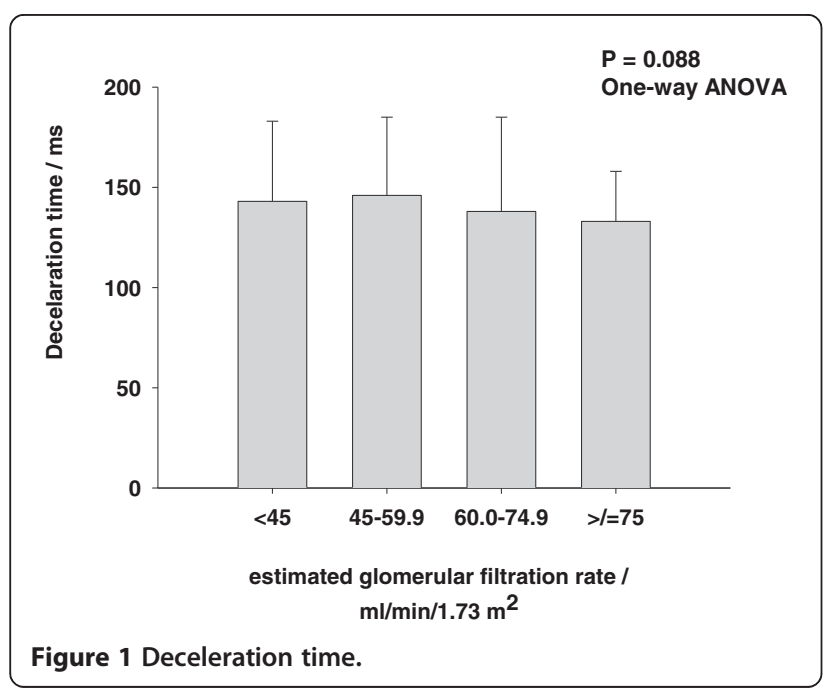

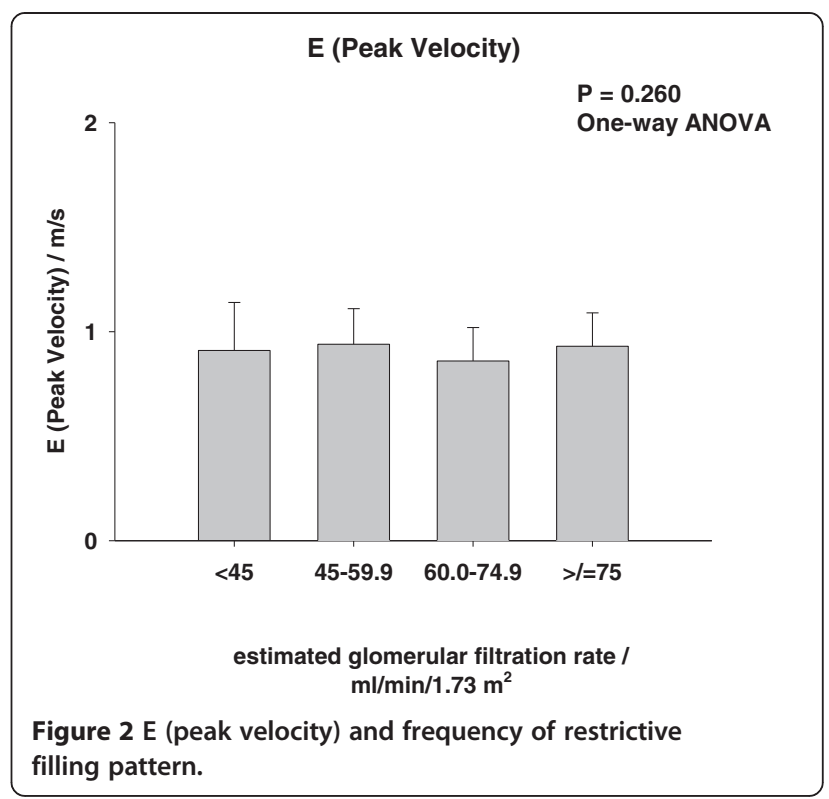

and NYHA class $(P=0.11)$, but differed to a minimal extent with regard to the frequency of left ventricular systolic dysfunction $(41 \%$ of the included patients had a LVEF $<0.50$ compared to $35 \%$ of the excluded patients $(P=0.003))$, which may be explained by the fact that $\mathrm{s}$-creatinine was reported more frequently in the randomized patients.

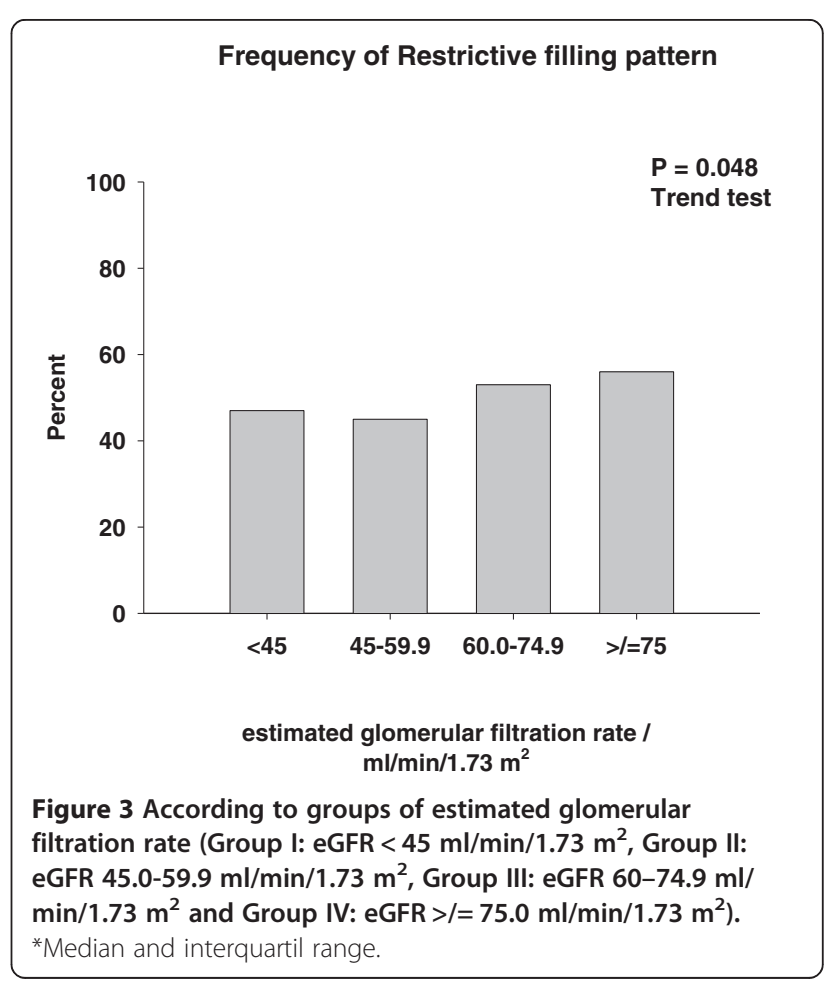




\section{Survival data}

Kaplan-Meier plots showing mortality rates according to groups of eGFR are presented in Figure 4 (LogRank $\mathrm{P}<0.001$ ). In the follow-up period 432 patients died.

Univariate and multivariable Cox proportional hazard models are presented in Table 2. Adjustment for RF (model 4 versus model 5) did not affect the parameter estimates for eGFR suggesting that the association between eGFR and mortality risk is not confounded by RF. Nor was the opposite the case (model 2 versus model 5) suggesting that nor is the association between RF and mortality risk confounded by eGFR. We did not observe any statistical interaction between eGFR, RF and mortality risk $(\mathrm{P}>0.05)$ nor was any interaction between mortality risk, eGFR $<30 \mathrm{ml} / \mathrm{min} / 1.73 \mathrm{~m}^{2}$ and $\mathrm{RF}(\mathrm{P}>0.05)$ observed. Furthermore, we did not observe any interaction between mortality risk, RF and ischemic versus non-ischemic cardiomyopathy $(\mathrm{P}>0.05)$, between mortality risk, RF and history of hypertension $(\mathrm{P}>0.05)$ and between mortality risk, RF and LVEF $>40 \%(\mathrm{P}>0.05)$. The prognostic significance of RF did, therefore, not interact with any of these important subgroups for which reason the patients were not divided further into subgroups.

\section{Discussion}

Our data suggest that eGFR is associated with mortality risk independently of RF in HF patients. We did not observe any coupling between renal function and severe diastolic dysfunction and likely other factors than impaired left ventricular filling explain the association between renal function and mortality risk in HF patients.

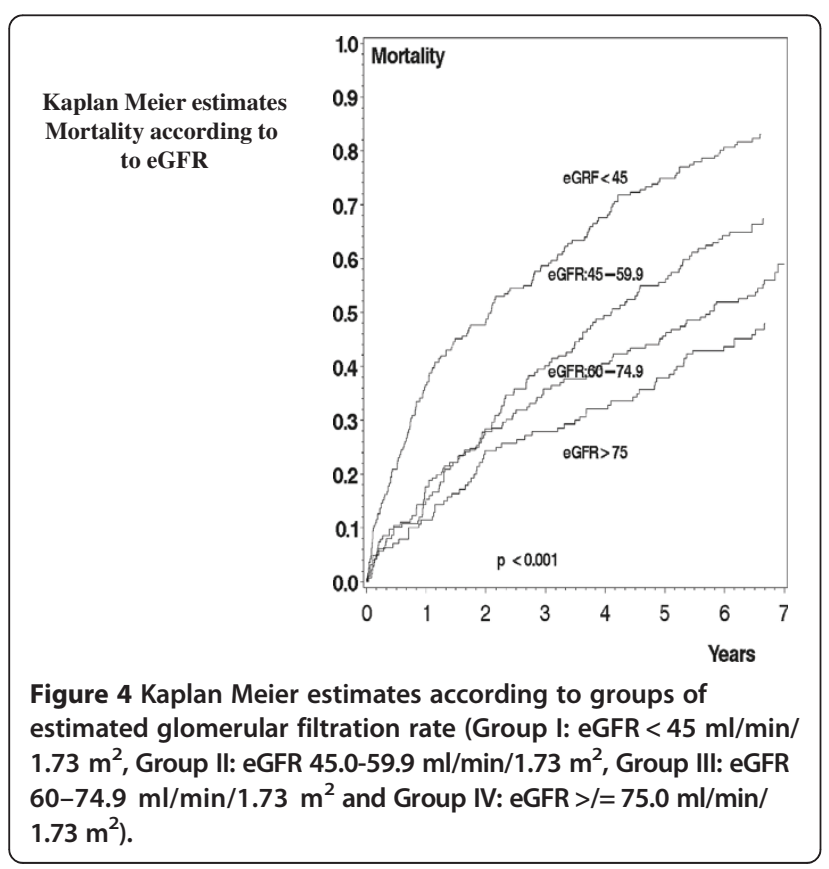

Table 2 Multivariate cox proportional hazard models

\begin{tabular}{|c|c|c|}
\hline Variable & $\begin{array}{l}\text { Hazard ratio }(95 \% \\
\text { confidence interval) }\end{array}$ & $P$ value \\
\hline Model 1: eGFR (Univariate) & -2LogL: 5172 & \\
\hline eGFR effect of a $10 \mathrm{ml}$ increase & $0.83(0.79-0.87)$ & $<0.001$ \\
\hline $\begin{array}{l}\text { Model 2: eGFR + traditional } \\
\text { confounders }\end{array}$ & -2LogL: 4614 & \\
\hline eGFR effect of a $10 \mathrm{ml}$ increase & $0.94(0.89-0.99)$ & 0.024 \\
\hline Model 3: RF (Univariate) & -2LogL: 5223 & \\
\hline RF & $1.38(1.14-1.66)$ & $<0.001$ \\
\hline $\begin{array}{l}\text { Model 4: RF + traditional } \\
\text { confounders }\end{array}$ & -2LogL: 4601 & \\
\hline RF & $1.54(1.26-1.89)$ & $<0.001$ \\
\hline $\begin{array}{l}\text { Model 5: eGFR + RF + traditional } \\
\text { confounders }\end{array}$ & -2LogL: 4595 & \\
\hline eGFR effect of a $10 \mathrm{ml}$ increase & $0.93(0.89-0.99)$ & 0.012 \\
\hline RF & $1.57(1.28-1.93)$ & $<0.001$ \\
\hline
\end{tabular}

Significant traditional confounders: age, sex, wall motion index, ischemic heart disease, diabetes, chronic obstructive pulmonary disease and NYHA class. Covariates were removed by backward elimination if $P>0.10$.

Previously, it has been observed that eGFR adds prognostic information to RF in outpatients with chronic HF and systolic dysfunction [23]. However, our data differ from the data by Bruch et al. [23] since we investigated patients admitted for acute decompensated heart failure with preserved and reduced LVEF and selected death as endpoint, in contrast to Bruch et al. [23] that selected a composite endpoint of death, admission and heart transplantation.

It has been repeatedly documented that eGFR is associated with increased long term mortality risk in patients with HF [1-6], but adjustment for diastolic function has not been performed in previous studies. Data from the DIG-trial has shown that renal dysfunction carried incremental prognostic information in HF patients with preserved LVEF, but diastolic function was not recorded [6]. We observed that adjustment for RF did not affect the parameter estimates for eGFR (Table 2). Consequently, RF cannot explain the excess mortality associated with renal dysfunction. Early mitral inflow peak velocity (E), E/ A-ratio and DT did not correlate to eGFR (Figures 1, 2 and Table 1), but the frequency of RF increased slightly with increasing eGFR (Figure 3). Accordingly, the severity of diastolic dysfunction did not increase with decreasing eGFR. This observation may reflect that RF alone does not reflect severity of diastolic dysfunction and intracardiac pressures accurately in this population [24] or that a diuresed HF population with a high prevalence of renal dysfunction is different from a chronic kidney disease population with cardiac dysfunction [19]. It could, of course also be a consequence of a type II error or selection bias. Lending indirect support to the recorded left 
ventricular filling patterns is the fact that symptom severity as assessed by NYHA class also was unaffected by renal function (Table 1) [25]. Finally, we did not observe any link between eGFR and RF in patients admitted with acute decompensated HF (Cardio-renal syndrome Type I). However, this observation does not exclude and association in e.g. acute and chronic reno-cardiac syndromes as previously observed [19].

Despite the close association with morality risk no randomized clinical trials have indicated that an intervention raised against renal dysfunction in HF can improve outcome. In acute decompensated heart failure ultrafiltration has been suggested to prevent deterioration of eGFR [26], however, it remains to be determined whether this improve long-term clinical outcome. Recently, despite encouraging early results, an adenosine receptor antagonist (Rolofylline) failed to improve renal function in HF patients [27] and the role for nesiritide is also unclear [28]. However, one non-randomized trial of a systematic diagnostic and therapeutic approach directed against renal dysfunction in HF patients has indicated that it is possible to obtain a significant improvement in kidney function [29], and in patients, where cardiac resynchronization therapy is indicated, this intervention may improve renal function [30]. Clearly the issue is complex. In some instances, such as during uptitration of ACE-inhibitors or angiotensin II receptor blockers, transient increase in s-creatinine is expected and accepted due to the well known long term benefit in terms of reduced morbidity and mortality. Thus, data suggest deterioration of renal function in HF are associated with a poor outcome, but optimal management depends on the clinical setting e.g. episodes of decompensation and hyperkalemia versus uptitration of an angiotensin converting inhibitor [31].

Based on the data from the present study as well as results of previous studies, eGFR may be considered independently associated with mortality risk in HF patients. The underlying mechanism is not clear. In particular, it is uncertain if low eGFR is associated with mortality mainly due to a renal factor (complicating intrinsic renal disease) or mainly due to the fact that low eGFR reflects low renal perfusion pressure because of poor cardiac output (cardiac factor in turn leading to poor prognosis). Although the present study suggest that the adverse prognosis associated with low GFR is largely unrelated to low LVEF or advanced diastolic dysfunction, the data cannot determine whether the excess mortality is related to an intrinsic renal mechanism or merely reflect a more extensive vascular disease and thus increased risk in these patients. It may be speculated that activation of the renin-angiotensin-aldosterone-system (RAAS) causes progression of renal dysfunction in HF similar to the development of diabetic nephropathy, which is supported by the CATS study (post myocardial infarction) [32].
However, aggressive blockade of the Renin-angiotensin II-aldosterone system (RAAS) in HF may lead to worsening renal function as seen in the CHARM-added [33], VALHeft [34] and VALLIANT [35] studies. A better understanding of the effect of RAAS inhibition on other renal endpoints like micro- and macroalbuminuria in HF is clearly needed $[16,36,37]$.

Attention should be paid to some methodological limitations of the present study. Our analyses are retrospective, but it seems unlikely that the observed associations between eGFR or RF and mortality risk reflect type I errors. Left ventricular filling pattern and s-creatinine data was only available in 669 out of 2881 patients and it may therefore be argued that our results reflect selection bias. However, the included patients did not differ from the excluded patients with respect to important clinical variables (internal validity acceptable) and selection bias would only appear if the associations between eGFR and RF or the associations between eGFR or RF and mortality risk were different in the excluded patients, which seems unlikely. Furthermore, the prognostic significance of RF and eGFR is in accordance with other studies (external validity acceptable) $[1,38,39]$. We used eGFR as estimate for GFR, and we did not analyze s-creatinine in a core lab, and this could lead to analytical variation. Furthermore, we defined severe diastolic dysfunction solely by RF and do not have data on left atria volume, left ventricular hypertrophy or tissue Doppler variables and it may therefore be argued that our results reflect inaccurate measurement of GFR and misclassification of severe diastolic dysfunction. However, recently it has been questioned whether a gold standard for diastolic function exists at all [40] and RF may be a reasonable estimate due to its extensive documented association with mortality risk in patients with HF and myocardial infarction [35,36]. Though, misclassification of severe diastolic dysfunction may have occurred due to lack of data on left atria volume, left ventricular hypertrophy and tissue Doppler. Patients with HF and preserved ejection (35\% of the present patients) constitute an inhomogeneous group and it may be argued that our results to some degree could reflect misclassification of HF [41]. The generalizability of our results should, therefore, be noticed. The present cohort neither reflects a cohort of acute decompensated HF patients with a reduced LVEF which are e.g "cold and wet" nor a cohort of patients with concentric left ventricular hypertrophy, normal LVEF and HF symptoms, rather it is a cohort of patients with dyspnoea requiring diuretics ("warm and wet"). The strengths of our study are the relatively large sample size with data on both eGFR and RF, the inclusion of patients with s-creatinine data $>200 \mathrm{umol} / \mathrm{L}$ (data from a screening database and not from a trial database), the long term follow up period without any lost to follow up and the large number of events. 


\section{Conclusions}

In HF patients restrictive filling of the left ventricle does not explain the increased mortality risk observed with decreasing eGFR. Factors other than impaired left ventricular filling explain the association between renal dysfunction and mortality risk. Whether the effect of eGFR and mortality risk in HF per se is causal deserves further study as does the association between eGFR and diastolic function in HF.

\section{Competing interests}

The authors declare that they have no competing interests.

\section{Authors' contributions}

MS: hypothesis, data analysis and manuscript preparation; JK: data collection, data analysis and manuscript preparation; CTP: data collection, data analysis and manuscript preparation; $\mathrm{CH}$ : data collection, data analysis and manuscript preparation; FG: hypothesis, data analysis and manuscript preparation; DA: data collection, data analysis and manuscript preparation; JEM: data collection, data analysis and manuscript preparation; LK: hypothesis, data collection, data analysis and manuscript preparation. All authors read and approved the final manuscript.

\section{Acknowledgements}

The ECHOS study was supported by unrestricted grants from Chiesi Pharmaceutical Company.

\section{Author details}

'Department of Cardiology, The Heart Centre and University of Copenhagen, Rigshospitalet, DK-2100 Copenhagen, Denmark. ${ }^{2}$ Department of Cardiology and Endocrinology, Hillerod University Hospital, DK-3400 Hillerod, Denmark. ${ }^{3}$ Department of Cardiology, Gentofte University Hospital, DK-2600 Hellerup, Denmark.

Received: 17 September 2012 Accepted: 26 November 2013 Published: 3 December 2013

\section{References}

1. Hillege HL, Girbes AR, de Kam PJ, et al: Renal function, neurohormonal activation, and survival in patients with chronic heart failure. Circulation 2000, 102:203-210

2. Hillege HL, Nitsch D, Pfeffer MA, Candesartan in Heart Failure: Assessment of Reduction in Mortality and Morbidity (CHARM) Investigators, et al: Renal function as a predictor of outcome in a broad spectrum of patients with heart failure. Circulation 2006, 113:671-678.

3. de Silva R, Nikitin NP, Witte KK, et al: Incidence of renal dysfunction over 6 months in patients with chronic heart failure due to left ventricular systolic dysfunction: contributing factors and relationship to prognosis. Eur Heart J 2006, 27:569-581.

4. Dries DL, Exner DV, Domanski MJ, Greenberg B, Stevenson LW: The prognostic implications of renal insufficiency in asymptomatic and symptomatic patients with left ventricular systolic dysfunction. J Am Coll Cardiol 2000, 35:681-689

5. Heywood JT, Fonarow GC, Costanzo MR, Mathur VS, Wigneswaran JR, Wynne J, ADHERE Scientific Advisory Committee and Investigators: High prevalence of renal dysfunction and its impact on outcome in 118,465 patients hospitalized with acute decompensated heart failure: a report from the ADHERE database. J Card Fail 2007, 6:422-430.

6. Ahmed A, Rich MW, Sanders PW, et al: Chronic kidney disease associated mortality in diastolic versus systolic heart failure: a propensity matched study. Am J Cardiol 2007, 99:393-398.

7. de Silva R, Nikitin NP, Bhandari S, Nicholson A, Clark AL, Cleland JG: Atherosclerotic renovascular disease in chronic heart failure: should we intervene? Eur Heart J 2005, 26:1596-1605.

8. Zittermann A, Schleithoff SS, Tenderich G, Berthold HK, Körfer R, Stehle P: Low vitamin $D$ status: a contributing factor in the pathogenesis of congestive heart failure? J Am Coll Cardiol 2003, 41:105-112.

9. de Silva R, Rigby AS, Witte KK, et al: Anemia, renal dysfunction, and their interaction in patients with chronic heart failure. Am J Cardiol 2006, 98:391-398.
10. Windram JD, Loh PH, Rigby AS, Hanning I, Clark AL, Cleland JG: Relationship of high-sensitivity C-reactive protein to prognosis and other prognostic markers in outpatients with heart failure. Am Heart J 2007, 153:1048-1055.

11. Mullens W, Abrahams Z, Francis GS, et al: Importance of venous congestion for worsening of renal function in advanced decompensated heart failure. J Am Coll Cardiol 2009, 53:589-596.

12. Cody RJ, Ljungman $\mathrm{S}$, Covit $A B$, et al: Regulation of glomerular filtration rate in chronic congestive heart failure patients. Kidney Int 1988, 34:361-367.

13. Assomull RG, Prasad SK, Lyne J, et al: Cardiovascular magnetic resonance, fibrosis, and prognosis in dilated cardiomyopathy. J Am Coll Cardiol 2006, 48:1977-1985.

14. Smilde TD, Hillege HL, Navis G, Boomsma F, de Zeeuw D, van Veldhuisen DJ: Impaired renal function in patients with ischemic and nonischemic chronic heart failure: association with neurohormonal activation and survival. Am Heart J 2004, 148:165-172.

15. McAlister FA, Ezekowitz J, Tonelli M, Armstrong PW: Renal insufficiency and heart failure: prognostic and therapeutic implications from a prospective cohort study. Circulation 2004, 109:1004-1009

16. Jackson CE, Solomon SD, Gerstein HC, CHARM Investigators and Committees, et al: Albuminuria in chronic heart failure: prevalence and prognostic importance. Lancet 2009, 374:543-550.

17. Damman $K$, van Deursen VM, Navis G, Voors AA, van Veldhuisen DJ, Hillege HL: Increased central venous pressure is associated with impaired renal function and mortality in a broad spectrum of patients with cardiovascular disease. J Am Coll Cardiol 2009, 53:582-588.

18. Smith GD, Phillips AN: Confounding in epidemiological studies: why "independent" effects may not be all they seem. BMJ 1992, 305:757-759.

19. Foley RN, Parfrey PS, Harnett JD, et al: Clinical and echocardiographic disease in patients starting end-stage renal disease therapy. Kidney Int 1995, 47:186-192.

20. Torp-Pedersen C, Køber L, Carlsen JE, et al: A randomised trial of a pre-synaptic stimulator of DA2-dopaminergic and alpha2-adrenergic receptors on morbidity and mortality in patients with heart failure. Eur J Heart Fail 2008, 10:89-95.

21. Akkan D, Kjaergaard J, Møller JE, Hassager C, Torp-Pedersen C, Køber L, EchoCardiography and Heart Outcome Study (ECHOS) investigators: Prognostic importance of a short deceleration time in symptomatic congestive heart failure. Eur J Heart Fail 2008, 10:689-695.

22. Smilde TD, van Veldhuisen DJ, Navis G, Voors AA, Hillege HL: Drawbacks and prognostic value of formulas estimating renal function in patients with chronic heart failure and systolic dysfunction. Circulation 2006, 114:1572-1580.

23. Bruch C, Reinecke H, Rothenburger M, Scheld HH, Whalley GA, Stypmann J. Breithardt G, Wichter T, Gradaus R: Transmitral flow patterns and the presence of chronic kidney disease provide independent and incremental prognostic information in patients with heart failure and systolic dysfunction. J Am Soc Echocardiogr 2007, 20:989-997.

24. Aurigemma GP, Zile MR, Gaasch WH: Lack of relationship between Doppler indices of diastolic function and left ventricular pressure transients in patients with definite diastolic heart failure. Am Heart $J$ 2004, 148:E12.

25. Packer M: Abnormalities of diastolic function as a potential cause of exercise intolerance in chronic heart failure. Circulation 1990, 81:78-86.

26. Costanzo MR, Guglin ME, Saltzberg MT, UNLOAD Trial Investigators, et al: Ultrafiltration versus intravenous diuretics for patients hospitalized for acute decompensated heart failure. J Am Coll Cardiol 2007, 49:675-683.

27. Massie BM, O'Connor CM, Metra M, et al: PROTECT Investigators and Committees. N Engl J Med 2010, 363:1419-28.

28. Chow SL, Peng JT, Okamoto MP, Heywood JT: Effect of nesiritide infusion duration on renal function in acutely decompensated heart failure patients. Ann Pharmacother 2007, 41:556-561.

29. de Silva R, Nikitin NP, Witte KK, et al: Effects of applying a standardised management algorithm for moderate to severe renal dysfunction in patients with chronic stable heart failure. Eur J Heart Fail 2007, 9:415-423.

30. Boerrigter G, Costello-Boerrigter LC, Abraham WT, et al: Cardiac resynchronization therapy improves renal function in human heart failure with reduced glomerular filtration rate. J Card Fail 2008, 14:539-546.

31. Jose P, Skali H, Anavekar N, Tomson C, et al: Increase in creatinine and cardiovascular risk in patients with systolic dysfunction after myocardial infarction. J Am Soc Nephrol 2006, 17:2886-2891. 
32. Hillege HL, van Gilst WH, van Veldhuisen DJ, et al: CATS randomized trial. Accelerated decline and prognostic impact of renal function after myocardial infarction and the benefits of ACE inhibition: the CATS randomized trial. Eur Heart J 2003, 24:412-420.

33. McMurray JJ, Ostergren J, Swedberg K, CHARM Investigators and Committees, et al: Effects of candesartan in patients with chronic heart failure and reduced left-ventricular systolic function taking angiotensinconverting-enzyme inhibitors: the CHARM-added trial. Lancet 2003, 362:767-771.

34. Cohn JN, Tognoni G, Valsartan Heart Failure Trial Investigators: A randomized trial of the angiotensin-receptor blocker valsartan in chronic heart failure. N Engl J Med 2001, 345:1667-1675.

35. Pfeffer MA, McMurray JJ, Velazquez E, Valsartan in Acute Myocardial Infarction Trial Investigators, et al: Valsartan, captopril, or both in myocardial infarction complicated by heart failure, left ventricular dysfunction, or both. N Engl J Med 2003, 349:1893-1906.

36. van de Wal RM, Asselbergs FW, Plokker HW, et al: High prevalence of microalbuminuria in chronic heart failure patients. J Card Fail 2005, 11:602-606.

37. Jose $\mathrm{P}$, Tomson C, Skali H, et al: Influence of proteinuria on cardiovascular risk and response to angiotensin-converting enzyme inhibition after myocardial infarction. J Am Coll Cardiol 2006, 47:1725-1727.

38. Meta-Analysis Research Group in Echocardiography (MeRGE) AMI Collaborators, Møller JE, Whalley GA, Dini FL, et al: Independent prognostic importance of a restrictive left ventricular filling pattern after myocardial infarction: an individual patient meta-analysis: meta-analysis research group in echocardiography acute myocardial infarction. Circulation 2008, 117:2591-2598.

39. Meta-analysis Research Group in Echocardiography (MeRGE) Heart Failure Collaborators: Independence of restrictive filling pattern and LV ejection fraction with mortality in heart failure: an individual patient meta-analysis. Eur J Heart Fail 2008, 10:786-792.

40. Solomon SD, Stevenson LW: Recalibrating the barometer: is it time to take a critical look at noninvasive approaches to measuring filling pressures? Circulation 2009, 119:13-15.

41. Nielsen $\mathrm{OW}$, Køber L, Torp-Pedersen C: Heart failure with preserved ejection fraction: dangerous, elusive, and difficult. Eur Heart J 2008, 29:285-287.

doi:10.1186/1471-2369-14-267

Cite this article as: Schou et al:: Renal dysfunction, restrictive left ventricular filling pattern and mortality risk in patients admitted with heart failure: a 7-year follow-up study. BMC Nephrology 2013 14:267.

\section{Submit your next manuscript to BioMed Central and take full advantage of:}

- Convenient online submission

- Thorough peer review

- No space constraints or color figure charges

- Immediate publication on acceptance

- Inclusion in PubMed, CAS, Scopus and Google Scholar

- Research which is freely available for redistribution

Submit your manuscript at www.biomedcentral.com/submit 